\title{
Estimating truck operating costs for domestic trips - case studies from Greece
}

\author{
Eleftherios SDOUKOPOULOS ${ }^{*}$, Maria BOILE ${ }^{1}$ and Afroditi ANAGNOSTOPOULOU \\ ${ }^{1}$ Centre for Research and Technology Hellas / Hellenic Institute for Transport, Athens, Greece
}

\begin{abstract}
The transport sector represents a vital component of national economies and has significant impacts on productivity and social welfare. In 2012, the transport sector in Europe was estimated to account for $3.7 \%$ of the European Gross Domestic Product (GDP) and $5.1 \%$ for employment. Road transport proves to be the predominant mode for moving goods within Europe holding a share of approximately $45.8 \%$ in 2012 (in ton-kms). In Greece, the share of road freight transport is significantly higher (98\%) indicating the importance of this sector for the Greek economy. To this end and considering the existing needs of road freight transport operators in Greece, the objective of this research is to establish an analytical and documented basis for estimating the operating cost of a truck on specific urban or national freight transport routes. To achieve this goal, an extended literature review has been conducted resulting in the identification of the main components comprising the total truck operating cost, which were then updated and validated through a series of personal interviews with selected road freight transport professionals. An excel-based application tool was also developed in order to facilitate operating cost estimates for different cases, through selection of the proper values of the relevant parameters. The resulting tool was used to analyse four test cases, which demonstrate the tool's usability and applicability. Results from this analysis have been also validated by industry experts and they reflect real-world transport scenarios.
\end{abstract}

Key words-Cost calculation tool, road freight transport, truck operating costs

\section{INTRODUCTION}

The transport sector represents a vital component of national economies and has significant impacts on productivity and social welfare. Efficient transport systems provide economic and social opportunities and result in better accessibility to markets, employment growth and investments [1]. In 2012, passenger and freight transport in Europe were estimated to account for about $3.7 \%$ of the European Gross Domestic Product (GDP) and 5.1\% of employment. Road transport proves to be the predominant mode for moving goods within Europe holding a share of about $45.8 \%$ in 2012 (in tonkms) [2]. In Greece, the share of road freight transport is significantly higher (98\%) indicating that goods are almost exclusively transported by trucks [3]. This highlights the importance of the sector for the Greek economy. Despite the above, the average annual turnover of the road freight transport sector has been steadily decreasing every year since 2008, when the impact of the financial crisis started becoming more apparent, reaching in 2012 a decrease of $46.2 \%$ within a 4 -year time period (Fig. 1).

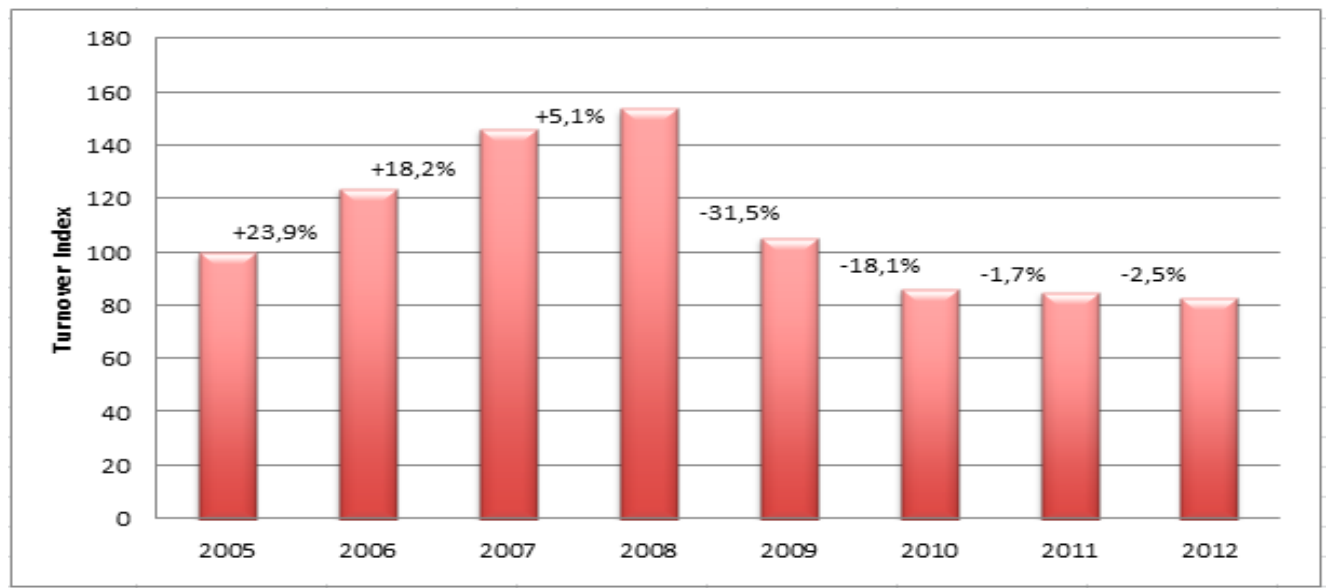


Figure 1: Average annual turnover index for the road freight transport sector in Greece [4] More specifically, as indicated in Fig. 1, the average annual turnover index for the road freight transport sector in Greece had been steadily increasing every year since 2005 until 2009 when a significant reduction of $31.5 \%$ was reported, attributed mainly to the sovereign economic crisis as well as to other directly or indirectly associated factors such as reduced productivity, business closure and growth of unemployment, lack of liquidity, fuel price increases, revaluation of toll costs, etc.

Considering the overall framework of the road freight transport sector in Greece, as outlined above, the absence of relevant research initiatives at a national level as well as the existing needs of the road freight transport professionals in Greece, the objective of this research is to establish an analytical and documented basis for estimating the operating cost of a truck on specific urban or national freight transport routes. To achieve this goal, an extended literature review has been conducted resulting in the identification of the main components comprising the total truck operating cost. Through personal interviews with selected road freight transport professionals, the aforementioned cost components were validated while additional ones were also considered in order to address some specific characteristics of the Greek road freight transport sector. The parameters considered for the estimation of the total truck operating cost fall under the following three categories: (a) general information describing the freight transport route and truck type under consideration, (b) cost components comprising the total fixed truck operating cost and (c) cost components comprising the total variable truck operating cost. Based on this methodology, an excel-based application tool has been developed to facilitate operating cost estimates for different cases, through selection of the proper values of the relevant parameters. The resulting tool was used to analyse four test cases, which demonstrate the tool's usability and applicability. Results from this analysis have been validated by industry experts and they reflect real-world transport scenarios.

The remainder of the paper is organized as follows: Section II provides a literature review of relevant research initiatives that have been undertaken at an international level as well as of limited number of studies that have been conducted at a national level. Section III presents the methodological approach that was followed for validating and updating the results of the review process enabling the identification of the main components comprising the total truck operating cost in Greece, considering all national specifications and characteristics. Those are being presented in Section IV along with the characteristics that are required for the route and truck under consideration. Organized in an excel-based application tool, the validated truck operating cost components are being estimated, in Section $V$, for four test cases reflecting real-world transport scenarios. The tool's usability, applicability as well as its potential limitations are being discussed within Section $\mathrm{VI}$ while conclusions and key observations are being drawn within the last section.

\section{LITERATURE REVIEW}

Several research initiatives have conducted in-depth analyses of the main components comprising the total truck operating cost, stemming mainly from the increased interest of trucking firms to minimize their costs as well as from policy makers in creative transportation funding strategies. Although such studies have been developed worldwide, their majority proves to be focusing mainly on the United States of America and Canada while several of them were initiated several years ago and are being frequently updated, every one or two years, with relevant data being collected by selected trucking firms.

Ref. [5] separated vehicle operating costs into running (e.g. fuel consumption, engine oil consumption, tire costs, maintenance costs, etc.) and standing costs (e.g. license, insurance, interest charges, etc.). Speed was indicated as the most important factor in fuel consumption while by increasing speed, maintenance costs were also found to increase. Vehicle size was identified also as another factor influencing fuel consumption and could be included in the model by using average axle numbers for each firm. Ref. [6] categorized the components that affect the truck operating cost into truck characteristics (e.g. weight, engine power, maintenance, etc.), local factors (e.g. speed limit, fuel price, labour cost, drivers' attitude, etc.) and road characteristics (pavement roughness, road width, etc.). Ref. [7] developed a spreadsheet simulation model projecting operating costs in terms of per mile, per hour, per trip and per ton-mile for various types of trucks and trip movements based on a variety of different parameters such as trip distance, 
payload, fuel price, interest rate, maintenance and repair, wages, owner/operator and lease status, miles per year and truckloads per year. Based on data provided by the American Trucking Association (ATA), Ref. [8] presented, for truckload general freight trucking, 13 expense categories (e.g. salaries, wages, fringes, operating and general supplies, tax and license, insurance, utilities, depreciation, etc.) and several key performance measures for three length of hauls i.e. under 250 miles, 250 to 500 miles and over 500 miles calculating the cost per mile for all three lengths. Ref. [9] provided a methodology and a spreadsheet model for estimating the truck operating costs based on fuel, maintenance, repair, tyres and depreciation costs thus considering some adjustment factors for cost based on pavement roughness, driving conditions and fuel price changes.

Ref. [10] developed a model for estimating the costs per vehicle-kilometre of the vehicle configurations, in the year 2000, based upon a summed-up component analysis tied to labour costs of drivers, fuel costs, repair and tire costs, registration and license fees, vehicle ownership costs (capital costs of depreciation of the vehicle including trailers and semi-trailers), cost of capital (financing costs for funds invested in vehicle purchase), insurance and administrative costs.

Ref. [11] estimated the operating costs for commercial vehicle operators in Minnesota. A survey of 186 firms that undertake commercial truck road movements was conducted. The average operating cost per kilometre for commercial vehicle operators was calculated from the survey responses. Results indicated that the translog and Cobb-Douglas models have approximately equal explanatory power in estimating the total cost from the data. The model also revealed the presence of nearly constant returns to scale, a finding consistent with earlier studies; an increase in output (total truckloads) of $1 \%$ was found to increase costs by $1.04 \%$.

Ref. [12] is the latest update of a relevant report that was initiated by the American Transportation Research Institute (ATRI) in 2008 with the objective to identify current and accurate operational costs based on data provided directly from motor carriers. The resulting dataset could then be used by both motor carriers as a high-level benchmarking tool and by government agencies for transportation improvement analyses. Marginal costs were divided into two groups: vehicle-based costs (e.g. fuel \& oil costs, truck / trailer release or purchase payments, repair \& maintenance, truck insurance premiums, permits and license, tires and tolls) and driver-based costs (e.g. driver wages and benefits). Average carrier costs per mile and per hour were calculated for the years 2008 to 2013 and relevant conclusions were drawn for this 6-year period based on the identified differences [13].

In Greece, prior to the research study which provided the basis for this paper, limited relevant research initiatives have been conducted. More specifically, Ref. [14] distinguished the total truck operating cost into five categories: costs related to the movement of trucks (e.g. fuel and oil costs, tires, repair and maintenance, etc.), fixed costs (e.g. capital costs, drivers wages, insurance, business profit, etc.), time costs, accident costs and depreciation of vehicles. Ref. [15] separated truck operating costs into two categories i.e. fixed costs (e.g. permits, licenses, insurance, costs for parking, repair and maintenance, tires, taxes, vehicle depreciation, legal and accounting services, truck wash, etc.) and variable costs (e.g. tolls, driver wages, fuel costs, communication costs, etc.)

In addition to the aforementioned research studies, it should be mentioned that quite a few online calculation tools such as Freight Metrics [16], the Decisive Cost Truck suite [17], the Total Cost Calculator of Mack Trucks [18], Costing of TruckScience [19], etc. have been developed and are available worldwide for estimating truck operating costs.

\section{Methodology}

The aforementioned literature review provided the basis for the identification of the main truck operating cost components, which were then validated and updated, through a series of personal interviews with selected road freight transport professionals in Greece, so that all national specifications and characteristics are taken into careful consideration. More specifically, the identified truck operating cost components as well as the required route and truck characteristics were presented to the interviewees who were then asked to validate them and provide any additional input regarding cost components that may be country-specific (e.g. insurances, license costs, etc.) and thus have not yet been included in the cost structure or on how traffic congestion may be approached (e.g. with different fuel consumption rates) so that a more accurate estimation is finally provided. Furthermore, for each cost component the interviewees were also asked to 
provide the most appropriate unit to be used (e.g. € per year or month) and for some of them their calculation method was discussed and agreed upon (e.g. truck and licence depreciation costs).

Once the truck operating cost structure was finalized and formulated in an excel-based application tool, a second round of interviews took place facilitating the tool's pilot-testing in four test cases reflecting real-world transport scenarios. It should be noted that road freight transport professionals providing different transport services (e.g. national, urban, specialized such as in construction sites, etc.) were contacted for this second round of interviews so that the tool's applicability could be tested in a variety of different cases.

\section{TOtal TRUCK Operating Cost COMPONENTS}

The final components for estimating the operating cost of a truck on specific urban or national freight transport routes were separated into fixed and variable operating costs and are being summarized in Tables 1 \& 2 while the required characteristics for the route and truck under consideration are being presented in Table 3.

Table 1: Fixed truck operating cost components

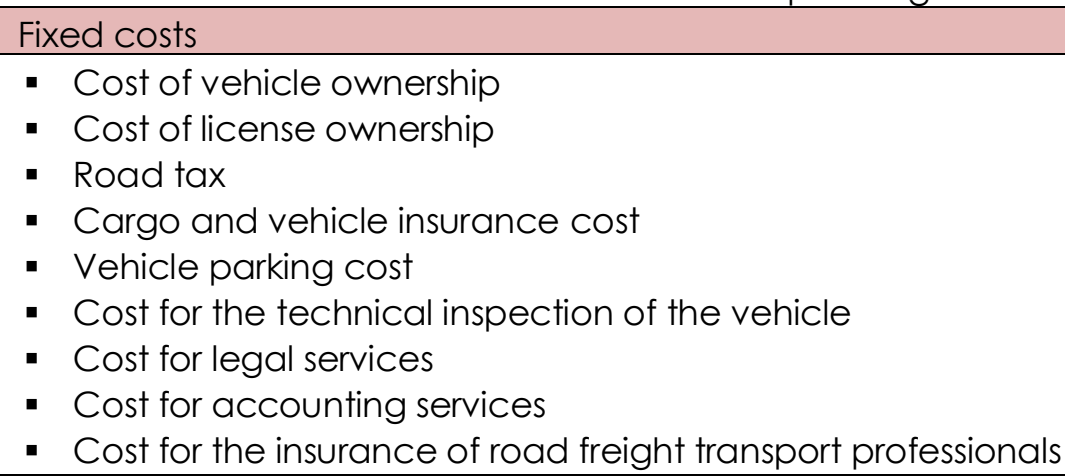

For vehicle and license costs, depreciation costs are being calculated taking into account, besides the cost itself, the time when the vehicle and license were purchased as well as the funding scheme that was selected (e.g. own capital or bank loan). All other costs are inserted on an annual basis, for the reference year, and according to the number of kilometres travelled by the truck under consideration, for that year, the total fixed operating cost per $\mathrm{km}$ can be estimated for a specific urban or national freight transport route. It should be noted at this point that not all costs are always applicable to all cases (e.g. vehicle parking costs).

Table 2: Variable truck operating cost components

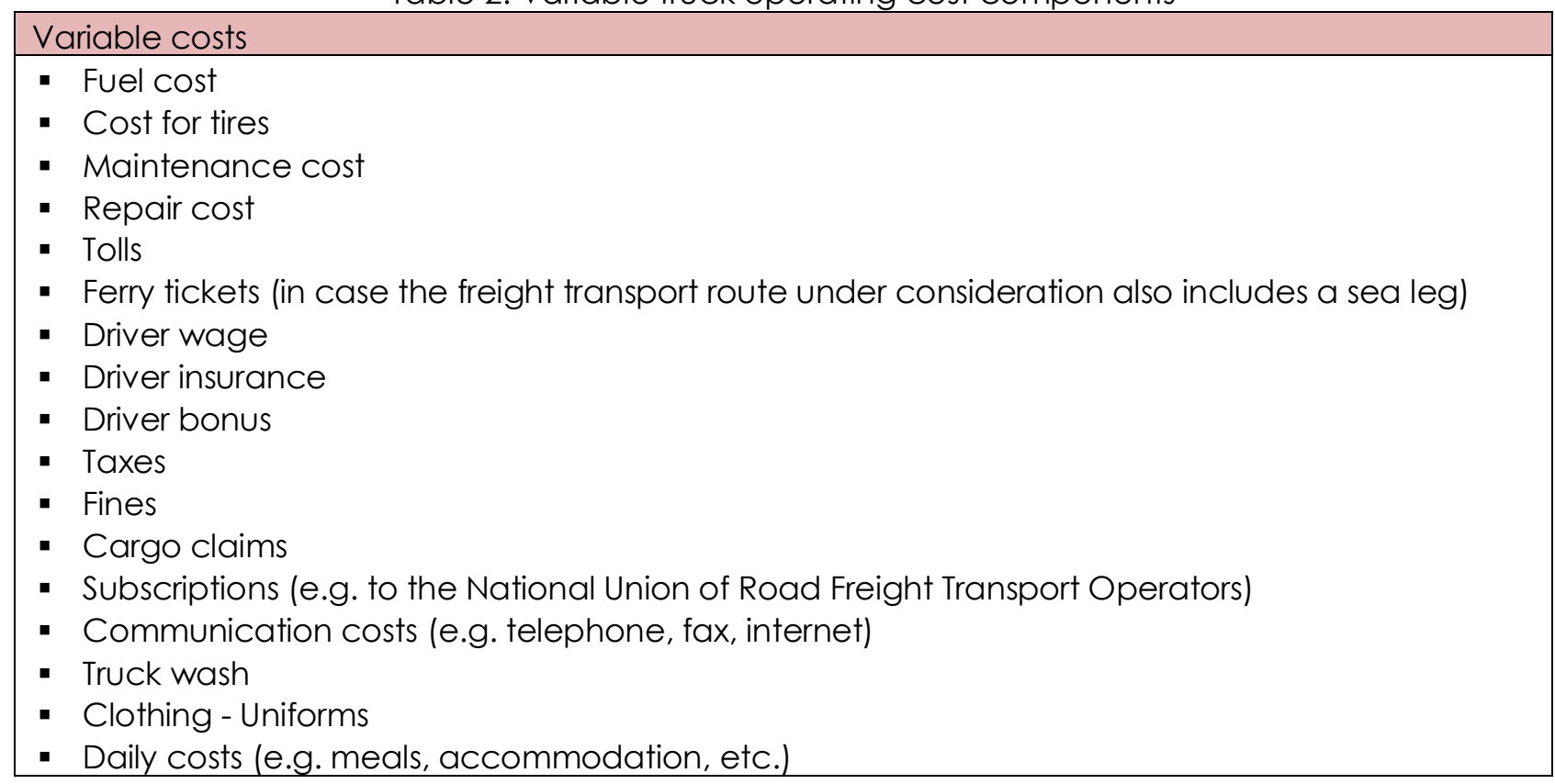




\section{- Miscellaneous expenses}

Fuel costs are being calculated based on the current, to that time, fuel price as well as on the average fuel consumption considering three different congestion levels (free flow, mediumcongested network, highly congested network) both for urban and national freight transport routes. Costs for maintenance and repair as well as taxes, fines, cargo claims and subscriptions (where applicable) are inserted on an annual basis for the reference year. Costs for tolls and ferry tickets are case specific and depend on the route under consideration, so they are calculated as such. Costs for tires are being calculated per km based on the type of tires used and the number of kilometres they are designed for. All other costs are being inserted on a monthly basis and are being projected to the reference year. To this end and based on the number of kilometres travelled by the truck under consideration, for that year, the total variable operating cost per $\mathrm{km}$ can be estimated.

The total operating cost per $\mathrm{km}$ is then calculated as a sum of the fixed and variable costs. To this end, and based on the total distance travelled for the route under consideration, the total operating cost for that route can be estimated. As indicated above, all costs are being calculated for a specific truck operating on a specific urban or national freight transport route. To this end, the characteristics of the truck and route under consideration should be indicated first. More specifically, the information depicted in Table 3 is required.

Table 3: Characteristics of the truck and route under consideration

\section{Truck and route characteristics}

- Origin and destination points

- Type of truck

- Age of truck

- Annual kilometres travelled

- Length of the freight transport route (in kms)

- Truck movement within the urban or national road transport network (\%)

- Traffic conditions in the urban or national road transport network (\%)

Three different types of trucks are being considered: (i) heavy duty trucks, operating mainly on national freight transport routes, (ii) light trucks, used mainly for transporting goods within urban areas and (iii) special trucks (e.g. tipper trucks, tanker trucks, etc.), which are used for transporting special cargo. The movement of the truck under consideration within the urban and the national road transport network should be also indicated (\%) while for each transport network three different congestion levels have been considered i.e. free flow, medium-congested network, highlycongested network imposing a different impact on the fuel consumption that is being taken into account.

\section{CASE Studies}

All the aforementioned cost components as well as the truck and route characteristics were structured into an excel-based application tool in order to facilitate operating cost estimates for different cases, through selection of the proper values of the relevant parameters. The resulting tool was used to analyse the following four test cases enabling the assessment of its usability and applicability. The routes that were selected represent real-world transport scenarios covering both national and urban freight transport routes as well as a more specific case of a truck operating within a construction site. As previously mentioned, the proper values of the relevant parameters were selected through a second round of personal interviews that were conducted with selected road freight transport professionals in Greece. The results of this analysis were also communicated and validated by industry experts.

\section{A. Route 1: Athens to Thessaloniki}

This route represents a national freight transport service from the capital of Greece, Athens, to Thessaloniki which is the $2^{\text {nd }}$ biggest city in Greece. The route's total distance is $550 \mathrm{~km}$ with the truck moving mainly within the national road transport network (90\%) and to a smaller extent (10\%) within 


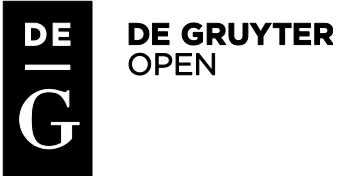

Logistics \& Sustainable Transport

Vol. 6, No. 1, November 2015, 41-49

doi: 10.1515/jlst-2015-0010

the urban areas of Athens and Thessaloniki for the pick-up and delivery of the goods respectively. Within the national road network, the truck under consideration was assumed to be moving in free flow conditions for the largest part of the route $(80 \%)$ experiencing only in certain cases medium $(15 \%)$ and high (5\%) congestion levels. The truck considered for this transport service is a 10 year-old heavy duty vehicle (40 tonnes weight) travelling, on average, $130.000 \mathrm{kms}$ per year.

The values that were selected for each of the truck operating cost components (fixed and variables) are depicted in Table 4. The total operating cost that was estimated for this route and for the specific truck, under the conditions described, is $516.8 €$, out of which $63.1 €$ represents the fixed cost component and $453.7 €$ represents the variable cost component. This result was then communicated and validated by industry experts.

\section{B. Route 2: Athens to Patra}

The $2^{\text {nd }}$ route that was selected also represents a national freight transport service from the capital of Greece, Athens, to the city of Patras. The route's total distance is $238 \mathrm{~km}$ with the truck moving mainly within the national road transport network (90\%) and to a smaller extent (10\%) within the urban areas of Athens and Patras for the pick-up and delivery of the goods respectively. Within the national road network, the truck under consideration was assumed to be moving in free flow conditions for the largest part of the route (70\%) experiencing in certain cases medium (25\%) and high (5\%) congestion levels. The same truck considered in the previous case was also considered for this route.

The values that were selected for each of the truck operating cost components (fixed and variables) are depicted in Table 4. The total operating cost that was estimated for this route and for the specific truck, under the conditions described, is $210.3 €$, out of which $27.3 €$ represents the fixed cost component and $183.0 €$ represents the variable cost component. This result was then communicated and validated by industry experts.

\section{Route 3: Industrial area of the West Attica region to Athens city centre (with intermediate stops)}

The $3^{\text {rd }}$ route that was selected represents an urban freight transport service from the industrial area of the West Attica region to the Athens city centre with four intermediate stops taking place for the delivery of goods. The route's total distance is $58 \mathrm{~km}$ with the truck moving exclusively within the urban area. The truck under consideration was assumed to be moving in free flow conditions for the largest part of the route (75\%) experiencing in certain cases medium (25\%) congestion levels. The truck considered for this transport service is a 7 year-old light truck travelling, on average, $35.000 \mathrm{kms}$ per year.

The values that were selected for each of the truck operating cost components (fixed and variables) are depicted in Table 4. The total operating cost that was estimated for this route and for the specific truck, under the conditions described, is $87.7 €$, out of which $18.2 €$ represents the fixed cost component and $69.5 €$ represents the variable cost component. This result was then communicated and validated by industry experts.

\section{Route 4: Internal route to a construction site}

The $4^{\text {th }}$ and last route that was selected represents a more specific case focusing on the movement of a special truck within the internal routes of a construction site. The route's total distance, taking into account the operating hours of the truck, is $230 \mathrm{~km}$. The truck under consideration was assumed to be moving exclusively into medium congestion levels in order to simulate the truck's low speed within the construction site. The truck considered for this transport service is a 4 year-old light tipper truck travelling, on average, $52.000 \mathrm{kms}$ per year.

The values that were selected for each of the truck operating cost components (fixed and variables) are depicted in Table 4. The total operating cost that was estimated for this route and for the specific truck, under the conditions described, is $365.0 €$, out of which $90.8 €$ represents the fixed cost component and $274.2 €$ represents the variable cost component. This result was then communicated and validated by industry experts. 
Table 4: Values of the fixed and variable truck operating cost components for the four selected routes

\begin{tabular}{|c|c|c|c|c|}
\hline Fixed operating costs & Route 1 & Route 2 & Route 3 & Route 4 \\
\hline $\begin{array}{l}\text { Cost for vehicle } \\
\text { ownership }\end{array}$ & $140.000 €$ & $140.000 €$ & $38.000 €$ & $115.000 €$ \\
\hline $\begin{array}{l}\text { Funding scheme } \\
\text { (vehicle) }\end{array}$ & Bank loan & Bank loan & Own capital & Bank loan \\
\hline $\begin{array}{l}\text { Cost for license } \\
\text { ownership }\end{array}$ & $9.000 €$ & $9.000 €$ & 35000 & 0 \\
\hline $\begin{array}{l}\text { Years since licence was } \\
\text { purchased }\end{array}$ & 14 years & 14 years & 8 years & 0 years \\
\hline $\begin{array}{l}\text { Funding scheme } \\
\text { (Licence) }\end{array}$ & Own capital & Own capital & Own capital & \\
\hline Road tax & $950 € /$ year & $950 € /$ year & $200 € /$ year & $650 € /$ year \\
\hline $\begin{array}{l}\text { Cargo and vehicle } \\
\text { insurance }\end{array}$ & $1.700 € /$ year & $1.700 € /$ year & $1.100 € /$ year & $2.250 € /$ year \\
\hline Vehicle parking cost & $1.200 € /$ year & $1.200 € /$ year & $1.200 € /$ year & $1.200 € /$ year \\
\hline $\begin{array}{l}\text { Cost for the technical } \\
\text { inspection of the vehicle }\end{array}$ & $155 € /$ year & $155 € /$ year & $260 € /$ year & $80 € /$ year \\
\hline $\begin{array}{l}\text { Cost for accounting } \\
\text { services }\end{array}$ & $550 € /$ year & $550 € /$ year & $660 € /$ year & $500 € /$ year \\
\hline Cost for legal services & $200 € /$ year & $200 € /$ year & $0 € /$ year & $0 € /$ year \\
\hline $\begin{array}{l}\text { Costs for the insurance of } \\
\text { road freight transport } \\
\text { professionals }\end{array}$ & $1.080 € /$ year & $1.080 € /$ year & $1.015,2 € /$ year & $4.500 € /$ year \\
\hline $\begin{array}{l}\text { Total fixed operating cost } \\
\text { for the selected route }\end{array}$ & $63,1 €$ & $27,3 €$ & $18,2 €$ & $90,8 €$ \\
\hline Variable operating costs & Route 1 & Route 2 & Route 3 & Route 4 \\
\hline \multicolumn{5}{|l|}{ Fuel cost } \\
\hline Fuel price & $1,405 € /$ It & $1,420 € /$ It & $1,450 € /$ It & $1,400 € /$ It \\
\hline $\begin{array}{l}\text { Average fuel } \\
\text { consumption for medium } \\
\text { congested urban freight } \\
\text { transport }\end{array}$ & $2,55 \mathrm{~km} / \mathrm{It}$ & $2,55 \mathrm{~km} / \mathrm{It}$ & $2,20 \mathrm{~km} / \mathrm{lt}$ & $2,00 \mathrm{~km} / \mathrm{lt}$ \\
\hline $\begin{array}{l}\text { Average fuel } \\
\text { consumption for medium } \\
\text { congested national } \\
\text { freight transport }\end{array}$ & $3,06 \mathrm{~km} / \mathrm{It}$ & $3,06 \mathrm{~km} / \mathrm{It}$ & $0,00 \mathrm{~km} / \mathrm{lt}$ & $0,00 \mathrm{~km} / \mathrm{lt}$ \\
\hline Cost for tires & $5.150 € / 200.000 \mathrm{~km}$ & $5.150 € / 200.000 \mathrm{~km}$ & $880 € / 100.000 \mathrm{~km}$ & $7.200 € / 80.000 \mathrm{~km}$ \\
\hline Maintenance cost & $800 € /$ year & $800 € /$ year & $1.000 € /$ year & $3.500 € /$ year \\
\hline Repair cost & $6.600 € /$ year & $6.600 € /$ year & $140 € /$ year & $2.500 € /$ year \\
\hline Tolls & $85 €$ & $21,4 €$ & $0 €$ & $0 €$ \\
\hline Ferry tickets & $0 €$ & $0 €$ & $0 €$ & $0 €$ \\
\hline Driver wage & $1.250 € /$ month & $1.250 € /$ month & $940 € /$ month & $1.000 € /$ month \\
\hline Driver insurance & $650 € /$ month & $650 € /$ month & $606 € /$ month & $0 € /$ month \\
\hline Driver bonus & $0 € /$ month & $0 € /$ month & $0 € /$ month & $0 € /$ month \\
\hline \multicolumn{5}{|l|}{ Taxes } \\
\hline Occupation tax & $130 € /$ year & $130 € /$ year & $130 € /$ year & $325 € /$ year \\
\hline Other taxes & $0 € /$ year & $0 € /$ year & $0 € /$ year & $0 € /$ year \\
\hline Fines & $360 € /$ year & $360 € /$ year & $800 € /$ year & $600 € /$ year \\
\hline Cargo claims & $360 € /$ year & $360 € /$ year & $120 € /$ year & $0 € /$ year \\
\hline Subscriptions & $25 € /$ month & $125 € /$ month & $16 € /$ month & $60 € /$ month \\
\hline \multicolumn{5}{|l|}{ Communication costs } \\
\hline Telephone, fax & $12 € /$ month & $12 € /$ month & $16 € /$ month & $40 € /$ month \\
\hline Internet & $8 € /$ month & $8 € /$ month & $8 € /$ month & $20 € /$ month \\
\hline
\end{tabular}




\begin{tabular}{|c|c|c|c|c|}
\hline Truck wash & $75 € /$ month & $75 € /$ month & $35 € /$ month & $100 € /$ month \\
\hline Clothing - Uniforms & $0 € /$ year & $0 € /$ year & $0 € /$ year & $0 € /$ year \\
\hline \multicolumn{5}{|l|}{ Daily costs } \\
\hline Accomondation costs & $0 € /$ month & $0 € /$ month & $0 € /$ month & $0 € /$ month \\
\hline Meals & $0 € /$ month & $0 € /$ month & $0 € /$ month & $0 € /$ month \\
\hline Miscellaneous expenses & $0 € /$ month & $0 € /$ month & $0 € /$ month & $0 € /$ month \\
\hline $\begin{array}{l}\text { Total variable operating } \\
\text { cost for the selected } \\
\text { route }\end{array}$ & $453,7 €$ & $183,0 €$ & $69,5 €$ & $274,2 €$ \\
\hline $\begin{array}{l}\text { Total operating cost for } \\
\text { the selected route }\end{array}$ & $516,8 €$ & $210,3 €$ & $87,7 €$ & $365,0 €$ \\
\hline
\end{tabular}

VI. DISCUSSION

The application of the excel-based cost calculation tool in the aforementioned four test cases and the validation of the respective results by industry experts demonstrated that the tool provides truck operating cost estimates with a good level of accuracy. To this end, it can serve as a useful guide for road transport freight professionals who can easily and timely estimate the truck operating cost for a specific route and for their specific vehicles. The excel-based format of the tool enables road freight transport professionals to insert once and save their trucks' characteristics and fixed cost components in different file versions which can then be used only for inserting the characteristics of a new route and the variable cost components for calculating the total truck operating cost. More accurate estimates may be provided ex-post as the experienced congestion levels and current, to that time, fuel costs can be determined. Estimates with a good level of accuracy may also be provided ex-ante, based on historic data. In the first case, variable cost components may be closely monitored and targeted actions may be taken for the possible reduction of some of them, while in the second case the tool may serve as a documented basis indicating the profit that road freight transport professionals will gain from the total fare offered to shippers / customers for specific transport services.

Although the tool is fully customizable and its generic nature ensures that a variety of different cases can be considered, some specific cases such as the $4^{\text {th }}$ test case, require certain attention and relevant modifications (e.g. the total distance was calculated based on the truck's operating hours and its slow speed within the construction site was simulated considering medium-congested levels for the whole route). For this purpose, the tool is accompanied with a manual indicating how each cost component is calculated, which unit is being used and what assumptions are being made. The basic structure of the tool, as such, may be transferred and used in other countries besides Greece but the development process indicated that a round of interviews with road freight transport professionals should be conducted so that all national specifications and characteristics are fully considered in the final cost structure.

\section{CONCLUSIONS}

Considering the overall framework of the road freight transport sector in Greece and the existing needs of the road freight transport operators, this paper aimed to establish an analytical and documented basis for estimating the operating cost of a truck on specific urban or national freight transport routes. Through the use of the relevant excel-based application tool that was developed, road freight transport professionals in Greece can easily and timely estimate, both ex-ante and expost, the truck operating cost for a specific route and for their specific vehicles and operating conditions. The tool is expected to serve as a useful guide for transport professionals for monitoring the different operating cost components possibly indicating areas where certain cost savings may be realized (e.g. eco-driving). Furthermore, this tool could also serve as a value-added service within a cargo brokerage and freight auction platform guiding the bidding of the different transport professionals for a specific service. The authors of this paper are coordinating a nationalfunded research project entitled "Advanced Cargo Transport Information Services - ACTIS" which is developing such a platform offering among different services the aforementioned tool. 
This research has been co-financed by the European Union (European Social Fund - ESF) and Greek national funds through the Operational Program "Education and Lifelong Learning" of the National Strategic Reference Framework (NSRF) - Research Funding Program: COOPERATION 2011. Investing in knowledge society through the European Social Fund.

\section{REFERENCES}

1. R. H. Ballou, Business Logistics: Supply Chain Management, 5th ed., Prentice-Hall, 2004.

2. European Commission, "EU Transport in Figures", Statistical Pocketbook, 2012.

3. E. Genitsaris, "Road freight transport in Greece", MSc Thesis, Aristotle University of Thessaloniki, 2010.

4. Hellenic Statistical Authority, "Road Freight Transport Study", Press Release, 2012.

5. C. Daniels, "Vehicle Operating Costs in Transport Studies: With Special Reference to the Work of the EIU in Africa", London: Economist Intelligence Unit, 1974.

6. T. Watanatada, A.M. Dhareshwar, P. R. S. Rezende Lima, P. M. O'Keefe and P. E. Fossberg "Vehicle Speeds and Operating Costs: Models for Road Planning and Management", The Highway Design and Maintenance Standards series, A World Bank Publication, Baltimore and London: The Johns Hopkins University Press, 1987.

7. M. Berwick and F. Dooley, "Truck Costs for Owner/Operators", Mountain-Plains Consortium Research Reports, Upper Great Plains Transportation Institute, North Dakota State University, 1997.

8. D.J. Forkenbrock, "External costs of intercity truck freight transportation", in Transportation Research Part A, vol. 33, 1999, pp. 505-526.

9. G. Barnes and P. Langworthy, "The Per-Mile Costs of Operating Automobiles and Trucks", Research Reports, Center for Transportation Studies, University of Minnesota, 2003.

10. Ray Barton and Associates, "Estimation of Costs of Heavy Vehicle Use per Vehicle-Kilometre in Canada", Transport Canada - Economic Analysis Directorate, 2006.

11. D. Levinson, M. Corbett and M. Hashami, "Operating Costs for Trucks", Working Series Number 000024 , University of Minnesota, Nexus Research Group, Minneapolis, 2004.

12. W. F. Torrey and D. Murray, "An Analysis of the Operational Costs of Trucking: a 2014 Update", American Transportation Research Institute, September 2014.

13. T. Trego and D. Murray, "An Analysis of the Operational Costs of Trucking", Proceedings of the 89th Transportation Research Board Annual Conference, Washington D.C., January 2010.

14. National Technical University of Athens, "Transport and Traffic - Non-conventional vehicles", Notes for the Master Course "Energy Production and Management", 2000.

15. C. Kaouki, "Analysis of the Cost for International Road Freight Transport Routes", MSc Thesis, University of Piraeus, 2008.

16. http://www.freightmetrics.com.au/Calculators/tabid/101/Default.aspx

17. http://decisivecost.com/Truck/Truck-Fleet-Selection.aspx

18. https://www.macktrucks.com.au/calculator/

19. http://www.truckscience.com/our-software/costing/

\section{AUTHORS}

A. Mr. Eleftherios Sdoukopoulos is with the Centre for Research and Technology Hellas / Hellenic Institute for Transport, Aigialeias 52, 15125, Marousi, Athens, Greece (e-mail: sdouk@certh.gr).

B. Dr. Maria Boile is with the Centre for Research and Technology Hellas / Hellenic Institute for Transport, Aigialeias 52, 15125, Marousi, Athens, Greece (e-mail: boile@certh.gr).

C. Dr. Afroditi Anagnostopoulou is with the Centre for Research and Technology Hellas / Hellenic Institute for Transport, Aigialeias 52, 15125, Marousi, Athens, Greece (e-mail: a.anagnostopoulou@certh.gr). 